\title{
Rendimento do cariru, Talinum triangulare, em sistema de cultivo hidropônico
}

\author{
Yeld cariru Talinum triangulare in hydroponics system
}

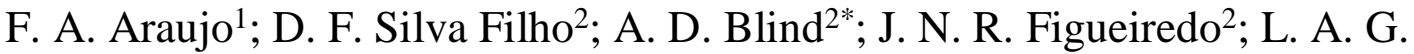 \\ Souza $^{2}$ \\ ${ }^{1}$ Agricultura no Tropico Umido/Laboratório de olericultura/CSAS, Instituto Nacional de Pesquisas da Amazonia, \\ 69067-375, Manaus-AM, Brasil \\ ${ }^{2}$ Corrdenação de Sociedade Ambiente e Saude/Laboratório de olericultura, Instituto Nacional de Pesquisas da \\ Amazonia, 69067-375, Manaus-AM, Brasil
}

*ariel.blind@inpa.gov.br

(Recebido em 20 de setembro de 2017; aceito em 26 de junho de 2018)

\begin{abstract}
O cariru é uma hortaliça folhosa, muito consumida na região norte do Brasil e atualmente demanda informações concretas sobre seu cultivo em sistema hidropônico. Neste sentido, objetivou-se avaliar o desempenho dessa espécie em sistema de cultivo hidropônico mini floating. $\mathrm{O}$ experimento foi conduzido em estufa convencional, adotando-se o delineamento inteiramente casualizado, com três tratamentos: T1reposição de nutrientes com nível de redução da Condutividade Elétrica (CE) em 25\%; T2- reposição de nutrientes com nível de redução da CE em 50\% e T3- reposição de nutrientes quando houver uma redução de $50 \%$ do volume inicial da solução nutritiva, e quatro repetições. As plantas avaliadas foram propagadas vegetativamente por estaquia em espuma fenólica e o cultivo em cubas plásticas com dimensões de 47,4 x $16,8 \times 16,3 \mathrm{~cm}$, com capacidade para 8 litros de solução nutriente. O conteúdo das massas frescas e secas e da composição química foram avaliadas em três colheitas, cada uma em um intervalo de 21 dias. Na avaliação, observou-se que, o cariru responde bem à redução da $\mathrm{CE}$ em níveis de $25 \%$ e 50\%, em função dos cortes sucessivos, sem a necessidade da troca total da solução nutritiva. Por outro lado, a cada colheita realizada houve redução na produção de biomassas frescas e secas na ordem de $23 \%$ em média para todos os tratamentos. Entre os macros e micronutrientes presentes na biomassa da parte vegetativa da planta, o potássio e ferro se destacaram com valores de $290,75 \mathrm{~g} \mathrm{~kg}^{-1}$ e $395 \mathrm{mg} \mathrm{kg}^{-1}$, respectivamente.
\end{abstract}

Palavras-chave: Hortaliça alternativa, solução nutriente, produção de biomassa.

The Cariru is a hardwood greenery, widely consumed in northern Brazil and currently requires concrete information about its cultivation in a hydroponic system. In this sense, the objective this work was to evaluate the performance of this species in mini floating hydroponic system. The experiment was conducted in a conventional greenhouse, with a completely randomized design, with three treatments: T1- nutrient replacement with an Electric Conductivity (EC) reduction level of 25\%; T2- nutrient replacement with EC reduction level of 50\% and T3- nutrient replacement when there is a reduction of 50\% of the initial volume of the nutrient solution and four replications. The evaluated plants were vegetatively propagated by phenolic foam cutting and cultivation in plastic tanks with dimensions of $47.4 \times 16.8 \times 16.3 \mathrm{~cm}$, with capacity for 8 liters of nutrient solution. The content of the fresh and dry masses, and the chemical composition, were evaluated in three harvests, each in a period of 21 days. In the evaluation, it was observed that cariru responds well to EC reduction at $25 \%$ and $50 \%$ levels, due to successive cuts, without the need for total exchange of the nutrient solution. On the other hand, for each harvest, there was a reduction in the production of fresh and dry biomasses in the order of $23 \%$ on average for all treatments. Among the macros and micronutrients present in the biomass of the vegetative part of the plant, the potassium and iron stood out with values of $290.75 \mathrm{~g} \mathrm{~kg}-1$ and $395 \mathrm{mg} \mathrm{kg}-1$, respectively.

Keywords: Alternative vegetable, nutrient solution, biomass production.

\section{INTRODUÇÃO}

Hortaliças folhosas são recomendadas nas dietas alimentares, porque apresentam baixo valor calórico e bons conteúdos de minerais, vitaminas e fibras prontamente disponíveis ao organismo [1]. O cariru, Talinum triangulare (Jacq.) Willd, é uma planta herbácea da família Portulacaceae, que possui raiz primária pivotante, caule ramificado, folhagem vigorosa, que atinge até $1 \mathrm{~m}$ de 
altura. Suas folhas são de cor verde-brilhante, suculenta, fixadas nas hastes, em forma de espiral. A principal utilização desta espécie na Amazônia é em saladas, sopas, carnes cozidas e como ingrediente do caruru, uma comida baiana preparada com quiabo e camarão [2].

Na Amazônia, a produção de hortaliças é pequena, estando restrita a um pequeno número de espécies. Por outro lado, o consumo é considerado bom, mas inferior ao de outras regiões. O preço de venda ao consumidor é elevado, limitando ainda mais a aquisição do produto. Por isso, a sociedade tem exigido a prática de uma agricultura mais eficiente e limpa. Para atender aos anseios populares, é necessário o aprimoramento de técnicas menos agressivas ao meio ambiente. Nesta direção, o cultivo hidropônico tem se apresentado como uma boa alternativa para produção de alimentos mais saudáveis, com qualidade e higiene, capaz de atender a um nicho de mercado de produtos hidropônicos cada vez mais competitivos e crescentes, com valores agregados.

A hidroponia é uma técnica alternativa de cultivo de hortaliças, baseada na utilização de uma solução aquosa, contendo os elementos minerais essenciais ao desenvolvimento dos vegetais, muito empregada no Brasil [3]. Por isso, a demanda de mercado de hortaliças cultivadas neste sistema de produção tem aumentado gradativamente nos últimos anos, incluindo a região norte do Brasil [2,3]. Estima-se que $35 \%$ a $40 \%$ de todos os vegetais que chegam à mesa do consumidor brasileiro sejam de origem hidropônica [4].

Existem vários sistemas hidropônicos utilizados na agricultura. Entretanto, os mais difundidos são: o sistema com substratos, sistema com técnica de fluxo laminar de nutrientes ou NFT (Nutrient Film Technique) e a técnica de cultivo na água, também conhecida como mini-floating ou flutuante, no qual não se estabelecem canais e sim recipientes com solução nutritiva, sobre bancada plana. $\mathrm{Na}$ técnica mini floating pode ser usado diversos recipientes, tais como baldes, bacias de qualquer tamanho, ou até mesmo piscina com mais de $20 \mathrm{~m}^{2}$. É bom salientar que este sistema depende oxigenação na solução com a função de manter o soluto nutritivo oxigenado, para evitar desordem fisiológica e até mesmo a morte das plantas [2].

Apesar do uso da técnica de hidroponia estar se destacando pela produção continua ao longo dos anos, especialmente em períodos de entressafra e garantir uma regularidade no fornecimento de produtos [5], ainda carece de estudos específicos na região onde pretende-se explorar o sistema com profissionalismo. Para que este sistema de cultivo ampare bons resultados ao produtor é necessário considerar a influência de vários fatores, entre eles destaca-se: salinidade, oxigenação, pH da solução nutritiva, intensidade de luz, fotoperíodo, temperatura e umidade do ar, condutividade elétrica (CE) e a forma de reposição da solução nutritiva [6].

Desta forma o presente estudo teve o objetivo de avaliar o rendimento do cariru sob duas formas de reposição de nutrientes: redução da condutividade elétrica e redução do nível da solução inicial, em três cortes sucessivos (colheita da parte aérea), no sistema de cultivo hidropônico mini - floating.

\section{MATERIAL E MÉTODOS}

O experimento foi realizado durante 64 dias, no período de 14/08/2012 a 17/10/2012, na Estação Experimental de Hortaliças Alejo Von der Pahlen do Instituto Nacional de pesquisa da Amazônia - INPA, localizado no km 14 da Rodovia AM 010, no município de Manaus, AM. O clima local é classificado como "Afi" no esquema de Köppen, com temperatura média de $27{ }^{\circ} \mathrm{C}$, precipitação média anual $2.300 \mathrm{~mm}$ e altitude de $72 \mathrm{~m}$ acima do nível do mar.

Os trabalhos foram conduzidos em casa de vegetação do tipo arco simples, coberta com filme de polietileno transparente de $150 \mu \mathrm{m}$. No interior da casa de vegetação utilizou-se uma bancada de madeira onde foram colocados os recipientes hidropônicos constituídos por floreiras de plástico com dimensões de 47,4 x 16,8 x 16,3 cm, e capacidade para 8 litros (Figura 1). 


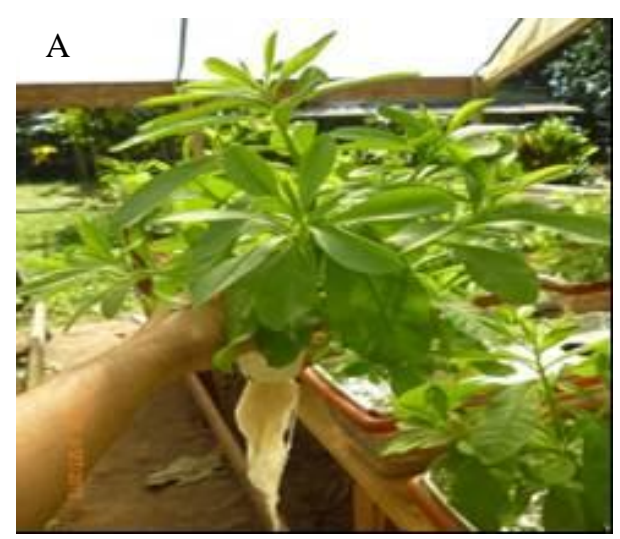

Figura 1. O cariru, Talinum triangulare (Jacq.) Willd (A) e aspecto das floreiras utilizadas no cultivo (B).

Os recipientes foram envolvidos por fita adesiva prateada, para refletir a luminosidade com objetivo de reduzir o aumento da temperatura da solução nutritiva. Cada unidade hidropônica era composta de um recipiente em cuja tampa foram feitos dois furos, para apoiar as mudas com pedaços de esponjas dentro de copos plásticos descartáveis de $180 \mathrm{~mL}$.

A formação das mudas de cariru foi feita através da técnica de propagação vegetativa por estaquia, a partir de plantas matrizes mantidas no Banco Ativo de Germoplasma da Coordenação de Sociedade, Ambiente e Saúde do Instituto Nacional de Pesquisas da Amazônia - CSAS/INPA, em Manaus, AM. Antecedendo a implantação do ensaio, as matrizes adultas que forneceram os propágulos foram cultivadas em vasos preenchidos com solo, em casa de vegetação. As estacas de cariru foram cortadas com estilete, no tamanho padrão de $10 \mathrm{~cm}$ de comprimento e $1 \mathrm{~cm}$ de diâmetro e colocadas à sombra por $24 \mathrm{~h}$ para cicatrizar os cortes. Posteriormente, foram depositadas em um béquer de $500 \mathrm{~mL}$ contendo um centímetro de lâmina de água mineral por quatro dias, tempo em que todas as estacas estavam enraizadas, e prontas para o transplante para os recipientes hidropônicos. No sistema hidropônico empregado mini-floating, as estacas foram envolvidas em espuma fenólica, dentro de copos plásticos descartáveis de $180 \mathrm{~mL}$, com furo de $3 \mathrm{~cm}$ de diâmetro para facilitar a passagem das raízes em direção à solução nutriente. A aeração da solução foi efetuada com aeradores de aquários, com dupla saída de ar, $110 \mathrm{v}-60 \mathrm{~Hz}$, pressão dos bicos de 0,012 Mpa e pedras porosas para dissipação do ar de forma homogênea.

O delineamento experimental adotado foi o inteiramente casualizado, constituído por três formas de suprimento de nutrientes e quatro repetições: T1- Reposição de nutrientes quando ocorreu a redução da CE em 25\%; T2- Reposição de nutrientes quando ocorreu a redução da CE em 50\%; e T3- Reposição de nutrientes quando ocorreu redução de $50 \%$ do nível do volume inicial da solução nutritiva independente da CE, conforme esquema da Figura 2.

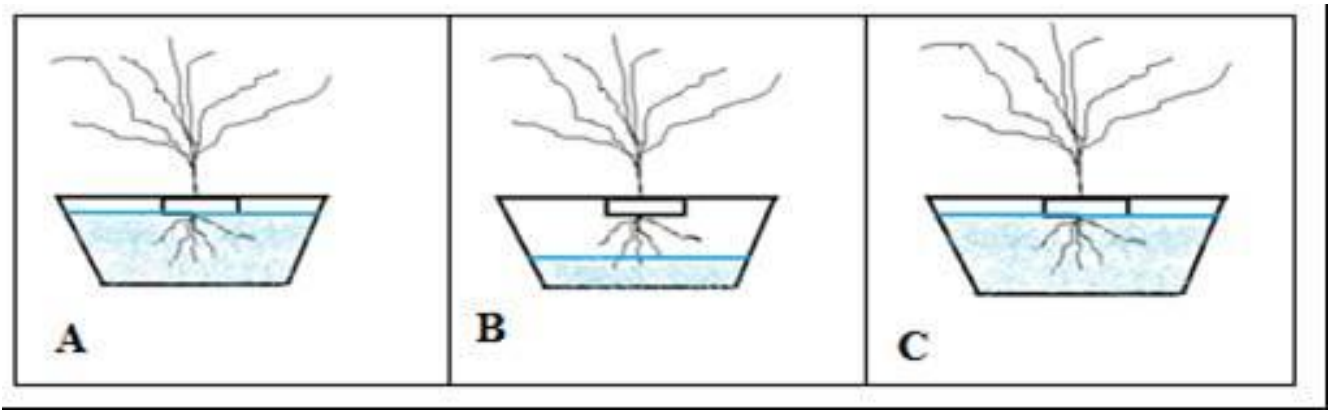

Figura 2. Esquema de reposição de solução nutritiva no Tratamento T3. Volume inicial (A), volume após uma redução de $50 \%$ (B) e volume após reposição de nutrientes $(C)$.

A solução nutritiva utilizada no experimento continha as seguintes concentrações de macro elementos: N-NO3- (12,0); N-NH4+ (1,71); P-H2PO4- $(1,0) ; \mathrm{K}+(4,6) ; \mathrm{Ca}^{2+}(3,56) ; \mathrm{Mg}^{2+}(1,66)$ e S-SO42- $(1,62) \mathrm{em} \mathrm{mmol} \mathrm{L-1}$. Para os micronutrientes as quantidades em $\mu \mathrm{mol} \mathrm{L}^{-1}$ foram 42,7 para 
o B;0,7 para $\mathrm{Cu}$; 34,0 para Fe;8,5 para Mn; 0,9 para Mo e 2,9 para Zn. Diariamente fazia-se o monitoramento da $\mathrm{CE}$, do $\mathrm{pH}$ e da reposição da água quando necessário. $\mathrm{O} \mathrm{pH}$ foi mantido numa faixa entre 5,7 $\pm 0,5$ adicionando-se $\mathrm{HNO} 30,1 \mathrm{~N}$ ou $\mathrm{KOH} 0,1 \mathrm{~N}$ para seu controle.

As colheitas foram realizadas a cada 21 dias (fenofase em que as plantas de cariru começam emitir o botão floral). O procedimento de colheita foi admitindo-se a parte aérea próximo à raiz, deixando 1 centímetro do caule para permitir uma rebrota e formar uma nova parte vegetativa da planta. Após cada corte da parte aérea, as plantas foram pesadas para obtenção da massa fresca, depois lavadas em água destilada, deionizada. As amostras foram colocadas para secar em estufa com circulação de ar a $60^{\circ} \mathrm{C}$ para obtenção da massa seca. Após a secagem, as amostras foram moídas e condicionadas em frascos fechados para realização das análises químicas dos seguintes elementos: fósforo, potássio, cálcio, magnésio, ferro, manganês, cobre e zinco. As análises químicas dos tecidos vegetais foram feitas conforme metodologia da Embrapa [7] para estes parâmetros. Os elementos $\mathrm{Ca}, \mathrm{Mg}, \mathrm{K}$ e $\mathrm{P}$ foram determinados por meio de digestão nitroperclórica, e os microelementos $\mathrm{Fe}, \mathrm{Mn}, \mathrm{Cu}$ e $\mathrm{Zn}$ por espectrofotometria de absorção atômica.

Os dados quantitativos das biomassas fresca e seca e do conteúdo da composição química dos tecidos vegetais foram submetidos a análises de variância e de regressão ao nível de $5 \%$ de probabilidade.

\section{RESULTADOS E DISCUSSÃO}

No acúmulo das biomassas fresca e seca da parte aérea das plantas observou-se declínio à medida que o primeiro corte foi realizado. É possível que este fato esteja relacionado a um desbalanço na absorção de cátions e ânions, porque durante as três colheitas da parte aérea não houve troca total da solução nutritiva, e sim, apenas reposição percentual da solução padrão (Figura 3).
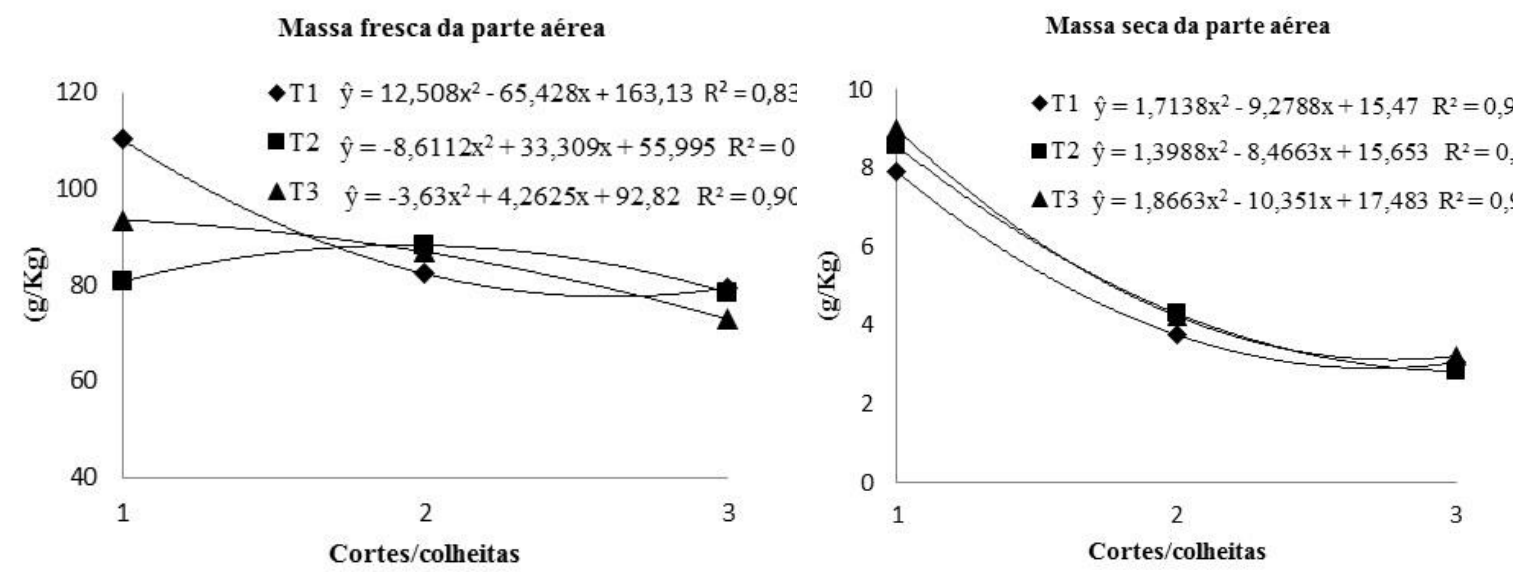

Figura 3: Equações ajustadas da analise de regressão e coeficientes de determinação para Massa fresca e massa seca da parte aérea do cariru durante três cortes sucessivos. INPA, Manaus, AM, 2012.

Para Bugbee (1995) [8] durante o cultivo das plantas em solução nutritiva, tem-se o esgotamento dos elementos da solução que variam em função do tempo. Normalmente, as diferenças na taxa de absorção de nutrientes podem ser rápida para $\mathrm{N}, \mathrm{P}, \mathrm{K}$ e $\mathrm{Mn}$, intermediária para $\mathrm{Mg}, \mathrm{S}, \mathrm{Fe}, \mathrm{Zn}, \mathrm{Cu}$ e Mo e lenta para $\mathrm{Ca}$ e $\mathrm{B}$, consequentemente essa diferença na absorção pode levar a um desequilíbrio na solução nutritiva e uma alteração no desenvolvimento da planta [9].

Vale salientar que, os resultados obtidos nesse trabalho não concordam com as curvas de acúmulo de massa fresca e seca de algumas espécies de olerícolas testadas por Echer et al. (2009)[10]. Estes pesquisadores relatam que geralmente as olerícolas apresentam três fases distintas na absorção de nutriente ao longo de seu crescimento: a primeira é lenta, posteriormente há uma intensa absorção até atingir o ponto máximo, a partir da qual ocorre um pequeno declínio na absorção dos nutrientes. O comportamento do cariru em função do sistema hidropônico ao qual foi submetido pode estar relacionado ao material genético usado experimentalmente, e pelos parâmetros cinéticos de absorção dos nutrientes, que são específicos a cada espécie ou cultivar, que podem afetar às características morfológicas e fisiológicas das plantas [11]. Desta forma é muito 
provável que o cariru tenha especificidade de requerimento em alguns elementos na primeira fase, ou seja, exatamente no processo de formação de raízes e folhas jovens.

As análises de variância detectaram diferenças em nível de 5\% de probabilidade entre os minerais absorvidos pelo cariru em todos os tratamentos. À medida que ocorreram os cortes da parte aérea ao longo do tempo de cultivo, surgiram diferenças no acúmulo de macro e micro nutrientes (Tabela 1).

Os nutrientes em solução nutritiva estão sujeitos à interações e reações inesperadas, e isto parece ser mais manifesto em regiões de clima quente. Essas interações podem ser por sinergismo (a absorção de um nutriente ou elemento químico intensifica a absorção de outro) ou antagonismo, em que a presença de um nutriente ou elemento químico inibe a absorção de outro [12]. Uma dessas interações pode ter ocorrido com o $\mathrm{K}^{+}$(Tabela 1), onde o mesmo declina drasticamente na presença elevada de $\mathrm{Ca}^{2+}$ e o SO $4^{2-}$ no primeiro corte já que que na presença de $\mathrm{Ca}^{2+}$ forma $\mathrm{CaSO} 4$, tornando indisponíveis para as plantas, acarretando um menor crescimento e consequentemente menores biomassas fresca e seca ao longo dos cortes.

Tabela 1: Teores de macro e micro elementos presentes na biomassa da parte aérea do carirú após sucessivos cortes em cultivo hidropônico Floating. INPA, Manaus, AM , 2012.

\section{$1^{\circ}$ CORTE AOS 21 DIAS}

\begin{tabular}{|c|c|c|c|c|c|c|c|c|}
\hline \multirow[b]{2}{*}{ Tratamentos } & $\mathbf{P}$ & $\mathbf{K}$ & $\mathbf{C a}$ & Mg & $\mathbf{F e}$ & $\mathbf{Z n}$ & Mn & $\mathbf{C u}$ \\
\hline & \multicolumn{4}{|c|}{$\ldots$} & \multicolumn{4}{|c|}{. } \\
\hline T1 & $6,85 \mathrm{~b}$ & $176,50 \mathrm{a}$ & $6,71 \mathrm{~b}$ & $4,78 \mathrm{~b}$ & $300,00 \mathrm{ab}$ & $99,75 \mathrm{a}$ & $330,25 \mathrm{a}$ & $19,50 \mathrm{~b}$ \\
\hline $\mathbf{T 2}$ & $8,18 \mathrm{a}$ & $159,50 \mathrm{~b}$ & $9,19 \mathrm{a}$ & $6,05 \mathrm{a}$ & 306,25 a & $88,50 \mathrm{~b}$ & $302,25 b$ & $19,25 \mathrm{~b}$ \\
\hline T3 & $6,83 \mathrm{~b}$ & $150,25 \mathrm{~b}$ & $6,26 \mathrm{c}$ & $4,79 \mathrm{~b}$ & $291,75 \mathrm{~b}$ & $92,25 \mathrm{~b}$ & $274,75 \mathrm{c}$ & $25,25 \mathrm{a}$ \\
\hline $\mathrm{CV} \%$ & 0,91 & 2,99 & 0,61 & 1,29 & 2,32 & 3,32 & 2,43 & 5,06 \\
\hline
\end{tabular}

$2^{\circ}$ CORTE AOS 42 DIAS

\begin{tabular}{|c|c|c|c|c|c|c|c|c|}
\hline \multirow[b]{2}{*}{ Tratamentos } & $\mathbf{P}$ & $\mathbf{K}$ & $\mathbf{C a}$ & Mg & $\mathbf{F e}$ & Zn & Mn & $\mathbf{C u}$ \\
\hline & \multicolumn{4}{|c|}{$\ldots \ldots . \mathrm{g} / \mathrm{Kg} \ldots \ldots \ldots \ldots \ldots \ldots \ldots \ldots \ldots \ldots \ldots \ldots$} & \multicolumn{4}{|c|}{$\ldots$} \\
\hline T1 & $6,81 \mathrm{a}$ & $160,75 \mathrm{~b}$ & $5,30 \mathrm{a}$ & $4,75 \mathrm{c}$ & $375,50 \mathrm{a}$ & $79,25 \mathrm{a}$ & $220 \mathrm{a}$ & $17,25 \mathrm{a}$ \\
\hline $\mathbf{T 2}$ & $6,79 \mathrm{a}$ & $120,50 \mathrm{c}$ & $4,90 \mathrm{~b}$ & 5,48 a & $303,75 \mathrm{~b}$ & $63,75 \mathrm{~b}$ & $176,25 \mathrm{~b}$ & $13,25 \mathrm{~b}$ \\
\hline $\mathbf{T 3}$ & $6,48 \mathrm{~b}$ & $190,75 \mathrm{a}$ & $4,44 \mathrm{c}$ & $5.05 \mathrm{~b}$ & $289,25 \mathrm{c}$ & $66,00 \mathrm{~b}$ & $178,75 \mathrm{~b}$ & $10,25 \mathrm{c}$ \\
\hline $\mathrm{CV} \%$ & 1,03 & 3 & 1,25 & 1,18 & 2,22 & 3,87 & 2,79 & 7,05 \\
\hline
\end{tabular}

$3^{\circ}$ CORTE AOS 63 DIAS

\begin{tabular}{|c|c|c|c|c|c|c|c|c|}
\hline \multirow[b]{2}{*}{ Tratamentos } & $\mathbf{P}$ & $\mathbf{K}$ & $\mathbf{C a}$ & Mg & $\mathbf{F e}$ & $\mathbf{Z n}$ & Mn & $\mathrm{Cu}$ \\
\hline & \multicolumn{4}{|c|}{$\ldots$} & \multicolumn{4}{|c|}{$\ldots$} \\
\hline T1 & $6,57 \mathrm{~b}$ & $91,00 \mathrm{~b}$ & $10,23 \mathrm{a}$ & $5,30 \mathrm{~b}$ & $3,29,75 \mathrm{~b}$ & $22,50 \mathrm{a}$ & $385,75 \mathrm{a}$ & $24,25 \mathrm{ab}$ \\
\hline $\mathbf{T} 2$ & $5,93 \mathrm{c}$ & $125,50 \mathrm{a}$ & $10,61 \mathrm{a}$ & $5,06 \mathrm{~b}$ & $395,00 \mathrm{a}$ & $21,50 \mathrm{a}$ & $342,25 \mathrm{~b}$ & $24,75 \mathrm{a}$ \\
\hline $\mathbf{T 3}$ & 8,07 a & $130,50 \mathrm{a}$ & $8,26 \mathrm{~b}$ & $6,19 \mathrm{a}$ & $303,00 \mathrm{c}$ & $11,00 \mathrm{~b}$ & $318,25 \mathrm{c}$ & $22,0 \mathrm{~b}$ \\
\hline $\mathrm{CV} \%$ & 1,2 & 3,05 & 3,48 & 2,56 & 1,74 & 7,27 & 1,59 & 5,55 \\
\hline
\end{tabular}

Os resultados revelaram que a parte aérea do cariru contém quantidades apreciáveis de micronutrientes. Os elementos $\mathrm{Zn}, \mathrm{Mn}$ e $\mathrm{Cu}$ com teores de 3 a 150, 20 a 500 e 5 a $20 \mathrm{mg} \mathrm{kg}^{-1}$ 
respectivamente, ficaram dentro das faixas recomendadas por Martinez e Clemente (2011) [5]. Apenas o microelemento ferro demonstrou incremento acima do recomendado pelos mesmos autores.

Nota-se que a absorção de $\mathrm{Fe}$ apresentou comportamento crescente em todos os tratamentos, com as médias máximas atingindo valores de 306,$25 ; 375,50$ e $395,00 \mathrm{mg} \mathrm{kg}^{-1}$, no primeiro, segundo e terceiro cortes, respectivamente. Estes valores são considerados elevados, tendo-se em vista que Martinez e Clemente (2011) [5] considera conteúdo adequado, quando varia de 50 a 100 mg. $\mathrm{kg}^{-1}$ para hortaliças folhosas em geral. Entretanto há registros na literatura de valores menores e mais elevados, encontrados em matéria de alface cultivada hidroponicamente. Cortez (1999)[13] e Neto et al. (2003)[14] mostraram índices de 227 a $5.015 \mathrm{mg} \mathrm{kg}^{-1}$ e de 137 a $139 \mathrm{mg} \mathrm{kg}^{-1}$, respectivamente. Como o micronutriente Fe é um componente importante da Hemoglobina, hortaliças como o cariru pode contribuir e ser recomendado para melhorar o suprimento desse mineral na dieta humana diária [15].

A absorção de cobre presente na biomassa seca do cariru pode-se apresentou uma conduta irregular para todos os tratamentos e as maiores taxas de acúmulo em torno de 19,50; 17,25 e 24,75 $\mathrm{mg} \mathrm{kg}^{-1}$, no primeiro, segundo e terceiro corte respectivamente. A rebrota desta espécie parece apresentar certa especificidade perante acumulo do elemento, porém é provável que consiga mobilizar este e outros elementos que poderiam estar em reservas no caule e até no sistema radicular.

O Mn apresentou uma conformação expressiva para absorção em todos os tratamentos, os mais significativos valores de manganês registrados foram de 330,$25 ; 220,00$ e $385,75 \mathrm{mg} \mathrm{kg}^{-1}$, no primeiro, segundo e terceiro cortes, respectivamente. Apesar do $\mathrm{Mn}^{2+}$ ter propriedades químicas semelhantes (raio iônico) aos cátions $\mathrm{Ca}^{2+,} \mathrm{Fe}^{2+} \mathrm{Zn}^{2+}$ e, especialmente, $\mathrm{Mg}^{2+,}$ a presença destes elementos pode inibir sua absorção e seu transporte. Mas ficou claro não ter havido a interação antagônica, porque do conteúdo de manganês na biomassa seca de cariru está dentro dos níveis de 20 a $500 \mathrm{mg} \mathrm{kg}^{-1}$, considerados normais por Martinez e Clemente (2011)[5].

Os mais expressivos valores de zinco registrados no experimento variaram de 99,75; 79,25; e $22,50 \mathrm{mg} \mathrm{kg}^{-1}$, no primeiro, segundo e terceiro cortes, respectivamente. Esse comportamento indica a existência de maior interação química do $\mathrm{Zn}$ com os demais nutrientes. $\mathrm{O}$ acúmulo de zinco no cariru ajustou-se ao modelo quadrático. Este elemento foi o único dos nutrientes que reduziu o seu conteúdo à medida que os cortes eram realizados. Pode ser que, à estaca de cariru ao envelhecer tenha menos necessidade de suprimento de zinco. Mas é bom salientar que no processo de absorção ativa, há competição entre os minerais pelos mesmos sítios de entrada na membrana celular e essa competição, pode inibir a absorção de outros elementos [12]. Nesse caso, o zinco pode ter sentido o efeito da competição iônica com outros nutrientes na solução nutritiva

As concentrações de minerais (Tabela 1) mostram que o cariru dispõe de uma significativa quantidade em sua parte vegetativa. Esses nutrientes podem ser aproveitados na alimentação humana, eles são importantes para diversas funções vitais do corpo (ácido-base e balanço hídrico).

Dentre os nutrientes absorvidos pela biomassa do cariru, o ferro se destacou com elevados valores, podendo contribuir significativamente para a gestão da saúde do homem, sendo recomendado na ingestão nutricional diária. Vegetais de folhas verdes ricos em ferro ( $\mathrm{Fe}$ ) são necessários e recomendados para combater anemia [11]. Na concepção de Manhães et al. (2008)[16] as folhas de cariru são consideradas excelente fonte de ferro, zinco e molibdênio, e o consumo de $200 \mathrm{~g} /$ dia desse alimento atenderia as necessidades diárias desses nutrientes.

Com relação aos tratamentos testados, o melhor desempenho ocorreu sob o efeito do T2 (reposição de nutrientes quando ocorreu redução da condutividade elétrica em 50\%), o qual apresentou na primeira colheita, as maiores médias significativas para quatro nutrientes, mostrando valores de 8,18; 9,19; 6,05 $\mathrm{g} \mathrm{kg}^{-1}$ para $\mathrm{P}, \mathrm{Ca}, \mathrm{Mg}$ e $306,25 \mathrm{mg} \mathrm{kg}^{-1}$ e Fe respectivamente. No segundo corte foi observado melhor incremento de 6,79 e $5,48 \mathrm{~g} \mathrm{~kg}^{-1}$ para $\mathrm{P}$ e $\mathrm{Mg}$. No terceiro corte os melhores resultados foram de 130,50 e 10,61 $\mathrm{g} \mathrm{kg}^{-1}$ para K e Ca e de 395,0; 22,50 e 24,75 $\mathrm{mg} \mathrm{kg}^{-}$ ${ }^{1}$ para $\mathrm{Fe}, \mathrm{Zn}$ e $\mathrm{Cu}$, respectivamente. 


\section{CONCLUSÃO}

O desempenho do cariru em sistema de produção hidropônico mini-floating permitiu realizar três colheitas sucessivas da parte aérea, em intervalos de 21 dias, sem a troca total da solução nutritiva.

O cultivo do cariru em sistema hidropônico pode ser feito com a redução $25 \%$ e $50 \%$ da (CE) representando uma economia de nutrientes, permitindo maiores lucros para o produtor.

Foi possível verificar que o cariru acumula alto conteúdo de Fe nas folhas e ramos tenros.

\section{AGRADECIMENTOS}

Ao Programa de Pós Graduação em Agricultura no Tropico Úmido e ao Instituto Nacional de Pesquisas da Amazônia

\section{REFERÊNCIAS BIBLIOGRÁFICAS}

1. Ohse S, Ramos DM, Carvalho SM, Fett R, Oliveira JLB. Composição centesimal e teor de nitrato em cinco cultivares de alface produzidas sob cultivo hidropônico. Bragantia, 2009. Mai;68(2)407-414, http://dx.doi.org/10.1590/S0006-87052009000200015

2. Araújo FS, Silva Filho DF, Souza LAG, Ribeiro JCD. Produção participativa de hortaliças com uso da técnica de Hidroponia, na área urbana de Manaus. In: Hiroshi Noda; Luiz Augusto Gomes de Souza e Danilo Fernandes da Silva Filho. (Org.). Agricultura Familiar no Amazonas: Conservação dos recursos Ambientais. $1^{a}$ ed. Manaus, Am: Wega, 2013, v. 1, p. 135-152.Jenkins PF. Making sense of the chest xray: a hands-on guide. New York: Oxford University Press; 2005. 194 p.

3. Santos OS. Hidroponia. Santa Maria: UFSM; 2009. 392 p.

4. Ninni K. Cultivo de alimentos hidropônicos cresce, mas ainda não é regulamentado. Disponível em:<http://www.abhidroponia.com.br/informativos-e-noticias/29-informativos-e-noticias/62-cultivo-dealimentos-hidroponicos-cresce-mas-ainda-nao-e-regulamentado $>$. Acesso em: maio, 2014.

5. Martinez HEP, Clemente JM. O uso de cultivo hidropônico de plantas em pesquisa. 1. ed. Viçosa, MG: Aprenda Fácil; 2011. 76p.

6. Silva AF, Pereira PRG, Santana LM, Albuquerque TCS. 2003. Crescimento e teores de nutrientes em alface influenciados por carbonato de cálcio e pela correção de $\mathrm{pH}$ da solução hidropônica. Horticultura Brasileira, 21: Suplemento CD.

7. EMBRAPA. Manual de análises químicas de solos, plantas e fertilizantes. Brasília, Embrapa Comunicação para Transferência de Tecnologia; 1999. 370 p.

8. Bugbee B. Nutrient management in recirculanting hydroponic culture. In: annualconferenceonhydroponics, 16. Tucson, 1995. Proceedings. Tucson, Hydroponic Society of America, 1995. p.15-30.

9. Resh HM. Cultivos hidropônicos. Nuevas técnicas de produccíon. $4^{\mathrm{a}}$. ed. Madrid: Ediciones Mundiprensa; 1997. 509p.

10. Echer FR, Dominato JC, Creste JE. Absorção de nutrientes e distribuição da massa fresca e seca entre órgãos de batata-doce. Horticultura Brasileira. 2009;27:176-182. http://dx.doi.org/10.1590/S010205362009000200010

11. Marschner H. Mineral nutrition of higher plants. New York: Academic Press; 1995.889 p.

12. Malavolta E. Manual de nutrição mineral de plantas. Piracicaba: CERES; 2006. 631 p.

13. Cortez GEP. Cultivo de alface em hidroponia associado à criação de peixes. Tese (doutorado), Faculdade de Ciências Agrárias e Veterinárias, Universidade Estadual Paulista, Jaboticabal; 1999. 75p.

14. Neto EB, Mendonça IF, Marrocos NRM, Barreto LP. Teores de micronutrientes em plantas de alface, em função do pH da solução nutritiva. Horticultura Brasileira. 2003;21:Suplemento. CD-ROM.

15. Omale J, Ugwu CE. Comparative studies on the protein and mineral composition of some selected nigerian vegetables. African Journal of Food Science. 2011;5(1):22-25.

16. Manhães LRT, Marques MM, Sabaa-srur AUO. Composição química e do conteúdo de energia do cariru (Talinum esculentum, Jacq.). Acta Amazonica. 2008;38:307-310. http://dx.doi.org/10.1590/S004459672008000200013 